\title{
AS CRÔNICAS DE JORGE SÉRGIO L. GUIMARÃES E AS REPRESENTAÇÕES DA SURDEZ ENTRE AS DÉCADAS DE 1950 E 1960
}

Tatiana Bolivar Lebedeff ${ }^{1}$

Diogo de Souza Madeira ${ }^{2}$

\section{Resumo}

Este trabalho propõe analisar e discutir textos publicados pelo escritor Jorge Sérgio L. Guimarães entre as décadas de 50 e 60 . O escritor, que era surdo, publicava suas pequenas crônicas, como colaborador, em três periódicos: Jornal das Moças, Shopping News do Rio e Jornal O Globo. Em 1961, os textos foram compilados no livro "Até onde o surdo vai". As narrativas apresentam indícios de um discurso hegemônico sobre a surdez ao mesmo tempo clínico e oralista, típico daquele período e anterior ao início dos estudos linguísticos e antropológicos das Línguas de Sinais e da surdez. O presente trabalho analisa os conceitos de surdez, oralismo e Língua de Sinais, ao mesmo tempo que apresenta Jorge Sérgio L. Guimarães como um importante cronista da surdez.

Palavras-chave: Representações; Surdez; Língua de Sinais; Oralismo; Memória

${ }^{1}$ Graduação em Educação Especial, Doutora em Psicologia do Desenvolvimento, Área de Libras e Programa de PósGraduação em Letras do Centro de Letras e Comunicação da Universidade Federal de Pelotas. Endereço: Avenida Ferreira Viana 2719 - apto 509 B - Pelotas - RS, Brasil. Endereço Eletrônico: tblebedeff@ gmail.com.

${ }^{2}$ Bacharelado em Comunicação Social - Habilitação Jornalismo, Mestre em Memória Social e Patrimônio Cultural, Instituto Federal de Educação, Ciência e Tecnologia Sul-rio-grandense. Endereço: Rua General Osório, n. 464/12, Pelotas - RS, Brasil. Endereço Eletrônico: madeira.azrael@gmail.com. 


\section{SURDEZ E REPRESENTAÇÕES}

As representações são, de acordo com Hall (1997, p. 183), uma parte essencial do processo pelo qual os significados são produzidos e compartilhados entre os membros de uma cultura. As representações implicam no uso de linguagem por meio de signos ou imagens, que significam ou representam as coisas.

As pesquisas na área dos Estudos Surdos têm evidenciado diferentes representações sobre a surdez, os surdos e as Línguas de Sinais. Os Estudos Surdos, na área da Educação, podem ser definidos, de acordo com Skliar, como:

[...] um território de investigação educativa e de proposições politicas que, por meio de um conjunto de concepções lingüísticas, culturais, comunitárias e de identidades, definem uma particular aproximação ao conhecimento sobre a surdez e os surdos. Nesses estudos, temos descrito a surdez nos seguintes termos (SKLIAR, 1998): uma experiência visual, uma identidade múltipla e multifacetada, que se constitui em uma diferença politicamente reconhecida e localizada, na maioria das vezes, dentro do discurso da deficiência (SKLIAR, 2000, p. 11).

Gesser (2008, p. 236) investigou narrativas observadas na interação em sala de aula de alguns professores surdos e seus alunos ouvintes, e constatou que as representações e os discursos no contexto da surdez limitavam-se a modelos conceituais opostos: modelo clínico versus modelo socioantropológico.

Com relação ao modelo clínico ou da deficiência, Obasi (2008, p. 457) salienta que existe um padrão social da deficiência e, se neste paradigma as representações das pessoas surdas são construídas a partir da presença de uma deficiência, os surdos serão vistos, portanto, como pessoas com deficiência. A partir desse modelo surgem diferentes representações, tais como de surdez como déficit (GIORDANI, 2004, p. 3) e como patologia, anormalidade, ou seja, como sujeitos a corrigir (THOMA, 2005, p. 252), entre outras. Lopes discute o impacto deste conjunto de representações na escola e, consequentemente, na sociedade:

Os surdos, quando não representados como sujeitos culturais, entram no rol dos desajustados, desintegrados da sociedade ouvinte, deficientes e incapazes de se desenvolverem sem o auxílio de grupos dominantes culturalmente. A escola não pode 
LEBEDEFF, T. B.; MADEIRA, D. S.

mais representar e contar os sujeitos com os quais trabalha, referendada em um único modelo de normalidade ou deficiência. Ela precisa procurar vê-los dentro do hibridismo em que estão envolvidos enquanto sujeitos diferentes e pertencentes a um grupo cultural em permanente construção e desconstrução de conceitos, comportamentos, valores [...] (LOPES; 1998, p. 114).

Entretanto, ao longo das últimas décadas, de acordo com Obasi (2008, p. 456), um discurso surdo cultural emancipatório tem tensionado uma mudança das representações. De acordo com a autora, este discurso surdo emerge das narrativas surdas sobre cultura e identidade, orgulho surdo e história surda. As representações de perfil socioantropológico discutem a surdez como minoria linguística (LANE, 1995, p. 171), como comunidade (LOPES, 2005), como produtores de cultura (KARNOPP, 2010, p. 171), como etnia (LANE, 2005, p. 291; CLAROSKARTCHNER, 2009, p. 64), entre outras.

Os surdos foram, portanto, medicados, educados, restringidos do acesso à língua ao longo dos anos, entre outras ações, como resultados dessas representações. Diferentes fontes podem evidenciar essas representações, tais como: discursos da política oficial (FIGUEIREDO, 2015), produção cinematográfica (THOMA, 2002), literatura (POKORSKI, 2014), etc. No Brasil, um autor surdo, pouco conhecido, Jorge Sérgio L. Guimarães, deve ser visto como uma dessas fontes. Guimarães escreveu crônicas, entre as décadas de 50 e 60, que formam um importante e significativo registro de um período histórico da comunidade surda brasileira em que a maioria dos autores é ouvinte. Sempre a partir de uma representação clínica, considerava a surdez como doença a ser tratada. As crônicas de Guimarães, neste sentido, não apresentam novidades nas representações sobre a surdez, os surdos ou as línguas de sinais, mas possibilitam compreender o impacto dessas representações no dia a dia de uma pessoa surda. Ou seja, as crônicas apresentam a ubiquidade dos discursos, das representações, no cotidiano de alguém que é "produto", consequência, desses próprios discursos.

\section{A PRODUÇÃO DO ESCRITOR SURDO}

O autor Jorge Sérgio L. Guimarães nasceu em 1933 no Rio de Janeiro, ficou surdo aos dois anos de idade em decorrência de crupe. $\mathrm{O}$ autor escrevia crônicas para periódicos que circulavam na cidade do Rio de Janeiro, entre as décadas de 50 e 60 do século XX: O Globo, O Jornal das Moças e o Jornal Rio News Shopping. As crônicas foram reunidas em um livro, 
publicado pela Gráfica Tupy, no Rio de Janeiro, em 1961, intitulado Até onde vai o surdo. As crônicas se apresentam autobiográficas por tratarem da sua vida cotidiana relacionada à surdez, nas quais o autor utilizava sempre a primeira pessoa do singular ou terceira pessoa do plural. Infelizmente, Jorge Sérgio Guimarães faleceu muito jovem, em 6/10/1973, vítima de enfarte, aos 40 anos de idade. A figura 1 mostra o autor em duas fotografias, cedidas pelo Jornal O Globo. O escritor estava em uma cerimônia, provavelmente no lançamento do seu livro, devido ao conjunto de exemplares em cima da mesa. É interessante notar que, mesmo sendo surdo profundo, está tentando fazer oralmente seu discurso, denotando a obrigatoriedade da fala aos surdos.

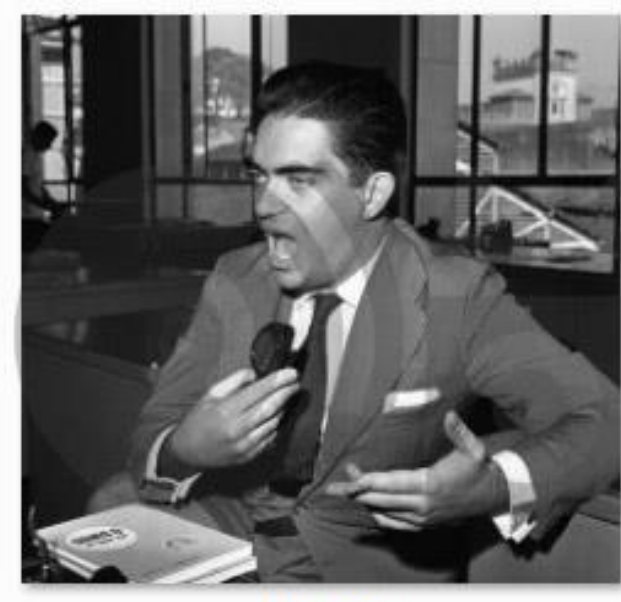

25484-001

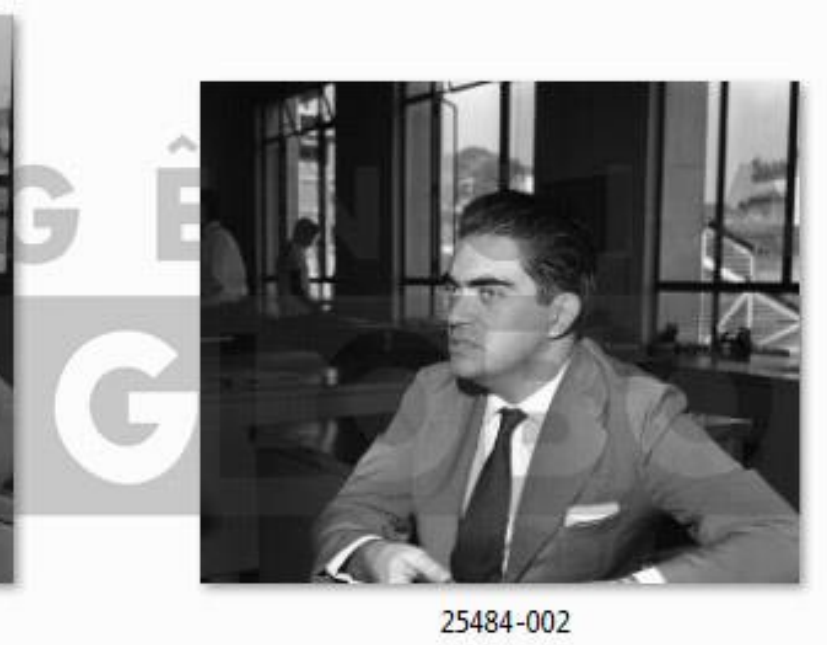

25484-002

Fig. 1: Jorge Sérgio L. Guimarães

Fonte: Fotografias cedidas pelo Jornal O Globo

O livro possui 112 páginas, contendo 41 pequenas crônicas escritas pelo próprio escritor. Além disso, contém prefácios de Pedro Bloch e Álvaro Moreyra. A figura na capa do livro, bastante chamativa, é de uma orelha da qual partem linhas circulares concêntricas, o que é entendida como símbolo da surdez (fig. 2). 
LEBEDEFF, T. B.; MADEIRA, D. S.

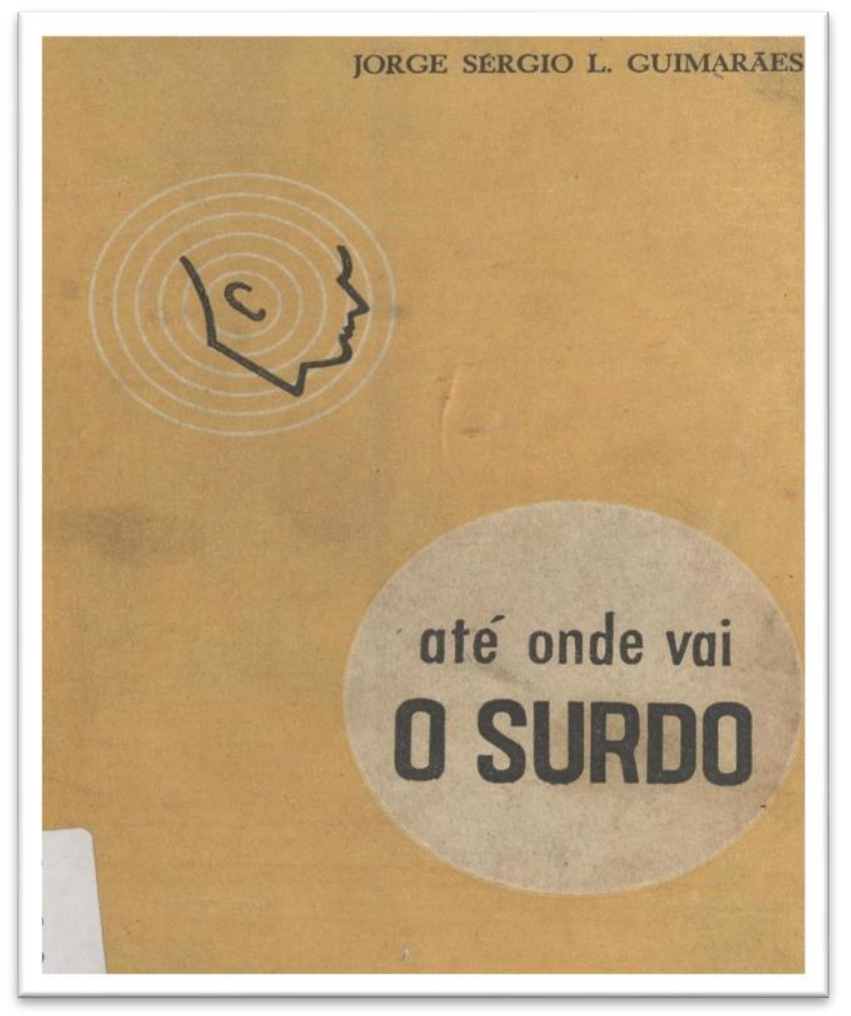

Fig. 2: Capa do livro Até onde vai o surdo de autoria de Jorge Sérgio L. Guimarães Fonte: Arquivo dos autores

Analisar os textos de Jorge Sérgio permitem compreender como um surdo transitava e como ele se compreendia enquanto surdo, entre discursos clínicos e políticas educacionais que proibiam a Língua de Sinais. Os textos denotam as representações sobre surdez, vigentes nas décadas de 50 e 60 do século XX, sendo um importante registro da memória da surdez.

Para Félix (2002), estudar a memória refere-se a uma nova concepção epistemológica e metodológica de compreensão do mundo cotidiano, que emerge da necessidade de indivíduos e grupos sociais de entender os significados, tanto de objetos materiais como de objetos imateriais. A autora discute, ainda, que na velocidade do próprio cotidiano o homem percebe a perda de suas referências mais imediatas e começa a questionar sua inserção social. Os surdos compõem uma minoria linguística com diferentes representações, discursos e registros "oficiais" que relatam muito mais uma história de medicalização, de normalização, de alijamento comunicativo do que de presença de língua e cultura.

Jorge Sérgio Guimarães escrevia crônicas para periódicos que circulavam na cidade do 
Rio de Janeiro: O Globo, O Jornal das Moças e o semanário Shopping News do Rio. O primeiro periódico foi fundado em 1925 e até o presente está situado no Rio de Janeiro. Atualmente é considerado um dos principais jornais nacionais. Nesse jornal, Guimarães publicava as suas crônicas sobre o cotidiano do surdo a convite do seu amigo Pedro Bloch.

O segundo, fundado em 1915 e instalado na mesma cidade, era voltado para o público feminino, anunciava novidades sobre moda, culinária, comportamento e dicas de beleza. O destaque está no excesso de material visual, por ser uma revista ilustrativa. Ela permaneceu ativa até dezembro de 1968. Algumas das crônicas de Guimarães foram publicadas nesse periódico, supostamente no espaço onde se podia publicar colunas não relacionadas com o tema central.

O terceiro é um semanário de anúncios de negócios, de mídia gratuita, fundado em São Paulo em 1953 e, posteriormente, com distribuição também no Rio de Janeiro.

As crônicas de Jorge Sérgio contam histórias do seu dia a dia, sua indignação com as condições educacionais e laborais dos surdos da época e impressões sobre a condição surda em outros lugares do mundo. Seus escritos contam também seus encontros com celebridades da época, tal como Helen Keller.

Os textos de Jorge Sérgio, mesmo os que narram encontros, como o com Helen Keller, sugerem sempre um sentimento de indignação e insatisfação com a educação dos surdos e a condição dos surdos na sociedade brasileira.

Os escritos do autor em estudo questionam as condições de educação e reivindicam direitos sociais aos surdos, como o de possuir carteira de habilitação, por exemplo. Impensável, naquele momento, mas apresentado na crônica "Surdos são bons motoristas?":

Ainda que pareça incrível, é verdade que os surdos, lá no exterior, podem guiar automóvel e, também, avião "teco-teco". E gozando dos mesmos direitos daquêles que dispõem de audição. Infelizmente, no Brasil, o Código do Trânsito não permite que nós tenhamos tal privilégio (GUIMARÃES, 1961, p. 26; publicado originalmente no Shopping News do Rio em 31/8/1958).

De acordo com os seus escritos, defendia a condição de ser surdo. Supõe-se que, na época, dentre muitos surdos, ele seria um dos poucos, no Brasil, a se expressar pela escrita, podendo assim, por meio dos meios de comunicação, divulgar questões consideradas invisíveis acerca da Surdez. Retoma-se o livro de Guimarães para discutir as representações de sua época, a 
LEBEDEFF, T. B.; MADEIRA, D. S.

partir de sua narrativa compreendendo sua produção como um registro da memória da comunidade surda brasileira. Nesse sentido, Candeau (2011) comenta que a memória se recusa a calar, pois ela é imperativa, onipresente, abusiva, invasora, e seu império deve-se à inquietude dos indivíduos e dos grupos em busca de si mesmos.

\section{REDUÇÃO TEMÁTICA PARA ORGANIZAÇÃO E ANÁLISE DE CATEGORIAS}

Os textos analisados fazem parte do livro intitulado "Até onde o surdo vai" que foi lançado em 1961. Para o estudo foi realizada uma redução temática objetivando a organização e a análise de categorias. A redução temática constitui-se em um procedimento gradual de redução do texto qualitativo (JOVCHELOVITCH e BAUER, 2008, p. 107), operando com generalização e condensação do sentido. Este procedimento de análise é mais comumente utilizado em entrevistas narrativas. Entretanto, como as crônicas são todas em primeira pessoa e narraram o dia a dia do autor, foi realizada uma adaptação para a análise, também, de textos literários com cunho auto-narrativo. A análise das entrevistas, ou, neste caso, dos textos auto-narrativos, pela redução temática tem, como produto final, uma interpretação das entrevistas/textos juntando estruturas de relevância dos informantes/autor com as do pesquisador. Essa fusão de horizontes, comentam Jovchelovitch e Bauer (2008, p. 109), é um processo hermenêutico.

A partir da redução temática foram organizadas seis categorias de análise: Política, Conceito de Surdez, Educação, Oralismo, Língua de Sinais e Língua Portuguesa. Para o presente texto foram selecionadas três categorias para discussão: Conceito de Surdez, Oralismo e Língua de Sinais. Como critério para a organização das categorias foi utilizada a recorrência de temas relativos à surdez. Esta recorrência apresentou discrepâncias, como, por exemplo, entre o conceito de surdez (maior número de comentários) e língua de sinais (tema com menor índice de recorrência). Neste caso, privilegiou-se, além da recorrência, o fato do excerto estar vinculado à temática da experiência com a surdez. Mesmo que a categoria Língua de Sinais apresente um número pequeno de recorrências, ela se constitui em foco de análise por sua importância no discurso do autor acerca da comunidade surda dos anos 60, a respeito de suas experiências e opiniões.

As categorias analisadas revelam a subjetividade do autor surdo. Ele usava a sua surdez, 
que foi mencionada em todas as crônicas selecionadas, como motivação para publicar seus escritos, mostrando que o escrever, ou seja, o narrar não lhe era um impasse. O destaque fica com a categoria Língua de Sinais que foi a menos prestigiada, mencionada em apenas duas crônicas. A razão desta baixa reputação é que a língua visual era proibida na época. Seu uso era considerado fracasso do processo educativo e de reabilitação médica. E, inclusive, talvez Guimarães não a usasse no seu dia a dia.

De certo modo, as categorias realizam um sombreamento umas sobre as outras, pois muitas vezes ao escrever sobre surdez o autor abordava também a "Língua Gestual” (Língua de Sinais) e o Oralismo. Porém, havia a necessidade didática e interpretativa de organizar focos de discussão. As categorias, portanto, não representam uma "pureza de significados" que emergem dos textos analisados, mas, podem ser compreendidos como temas caros para o autor.

\subsection{Surdez}

A surdez era vista como uma doença que deveria ser "curada" ou, pelo menos, "normalizada". A crônica "Causas da surdez" evidencia a concepção de surdez como doença, visto que a tônica é a busca da cura:

Recentemente, li com entusiasmo um artigo numa revista que falava numa senhora, vítima de ostoscleróse, (doença que ataca um terço de pessoas portadoras de deficiência auditiva), foi operada por um especialista competente, devolvendo-lhe a audição. Tratase da intervenção chamada "mobilização do estribo" que, para esclarecer bem, não serve para outros tipos comuns de surdez (GUIMARÃES, 1961, p. 68; publicado originalmente no Jornal das Moças em 7/4/1960).

Avanço importante da medicina, no campo otológico, são as operações de fenestração, eficazes em muitos casos de otosclerose, na recuperação da audição. Quanto às comentadíssimas experiências do enxerto de diversos órgãos nos cães, realizadas pelo cirurgião russo Dr. Vladimir Demikov, imagino que, dentro de poucos anos, será uma realidade a tentativa da ligação dos nervos auditivos, em substituição aos atrofiados. Acredito que, quando isso acontecer, contribuirá imensamente para a felicidade dos surdos do mundo inteiro (GUIMARÃES, 1961, p. 67; publicado originalmente no Jornal das Moças em 7/4/1960).

A busca pela cura médica da surdez aparece em outros escritos, tais como a crônica "Meu Deus, isto fala!” (GUIMARÃES, 1961, p. 59; publicado originalmente no Jornal das Moças em 28/01/1960). No texto, o autor elogia as tentativas de Alexandre Graham Bell na busca da cura da 
LEBEDEFF, T. B.; MADEIRA, D. S.

surdez através de aparelhos, que culminou no que se conhece hoje por telefone.

Além da concepção de doença, também surgem, nos textos do escritor, a surdez como defeito e destino, como pode ser lido na crônica "Não me envergonho de ser surdo":

Por experiência própria, posso afirmar que a deficiência auditiva não é um sério obstáculo, é apenas um defeito humano. Afinal de contas, quem não os tem? Será que alguém leva uma vida perfeita? Acredito que não. Portanto, sejamos realistas. Cada um de nós tem seu caminho traçado, como é a vontade divina. A principal questão é aceitar o que possa vir a acontecer (GUIMARÃES, 1961, p. 15; publicado originalmente no Shopping News do Rio em 30/3/1958).

A educação teve destaque em várias das crônicas de Jorge Sérgio Guimarães. Com relação ao conceito de surdez, chama a atenção a diferença entre "surdo-falante" e "surdo-mudo" presente na crônica "Viva o Progresso":

Tecnicamente, os professores consideram "surdos-falantes" os que se comunicam normalmente com as pessoas ouvintes, graças à boa orientação recebida desde a infância, e "surdos-mudos" aquêles que não falam, mas fazem mímica para se expressarem, o que não é meu caso. (GUIMARÃES, 1961, p. 13; publicado originalmente em O Globo 21/10/1959).

Já outras crônicas, entre elas “Tambaú: terra dos milagres”, explicitam as tentativas não médicas da cura da surdez com benzimentos e curas milagrosas:

Observando tais casos dolorosos, senti uma certa revolta, mas, em compensação, aprendi com eles algo mais importante que o próprio infortúnio: a esperança nunca morre, enquanto prevalecer a fé humana. Esta foi a lição mais preciosa que recebi naquele momento. No meio do povo simples e pobre, a par dos comentários, soube que dois pequenos irmãos que não ouviam ficaram curados. A filha do prefeito local não enxergava e, a pedido deste, o bondoso padre Donizetti rezou com muito fervor para Nossa Senhora da Aparecida, para conceder a recuperação da vista àquela menina infeliz (GUIMARÃES, 1961, p. 61; publicado originalmente no Jornal das Moças em 25/02/1960).

Jorge Sérgio Guimarães não comenta, em suas crônicas, sobre impedimentos ou preconceitos sofridos pessoalmente por conta de sua surdez. Entretanto, em vários momentos ele chama a atenção para preconceitos sociais frutos do encontro surdo-ouvinte. A palavra preconceito surge nas crônicas "Inesquecíveis" e "O Milagre da fala":

Sempre que aparece um filme, cujo título principal gira em torno da surdez, não deixo de assistir, tal é a minha grande curiosidade. Vendo a fita, esqueço-me das tristezas, dos 
preconceitos sociais, etc. Creio que todos os surdos sentem a mesma sensação (GUIMARÃES, 1961, p. 29; publicado originalmente no Shopping News do Rio em 28/9/1958)

É verdade que persiste, ainda, o velho preconceito, em grande número de pessoas, de que o deficiente da audição permanecerá mudo em consequência da surdez, e que jamais se adaptará ao convívio humano, apenas pelo fato de não ouvir. Mas que concepção absurda! Esta crença popular, fruto da ignorância, precisa ser eliminada para o bem da humanidade.

(GUIMARÃES, 1961, p. 21; originalmente publicado no Shopping News do Rio em 29/6/1958).

De modo geral, os discursos sobre a surdez que emergem das crônicas de Sérgio Guimarães evidenciam representações pelo viés da doença, da falta, da incapacidade. Os textos apontam alternativas para a surdez em duas direções principais: para a proibição do que ele denomina de "Alfabeto Manual”, ou seja, a Língua de Sinais e para a expansão e consolidação do Oralismo, método educacional vigente na época e, pelo qual Guimarães foi escolarizado. Ambos se constituem nas próximas categorias a serem discutidas.

\subsection{Língua de Sinais}

Sobre a Língua de Sinais, Lebedeff e colaboradores (2012, p. 232) citam Diniz (2011), o qual relata que registros históricos indicam a existência de uma Língua de Sinais Brasileira autóctone. Esta entrou em contato com a Língua de Sinais Francesa a partir de 1855, com a vinda de um professor surdo francês, Eduard Huet, para fundar o que é hoje o Instituto Nacional de Educação de Surdos - INES, localizado no Rio de Janeiro, capital do Império, na época. Todavia, assim como em muitos países, a Língua de Sinais usada pelos surdos brasileiros foi proibida nas escolas a partir do Congresso de Milão, ocorrido em 1880, que definiu marcos para a Educação de Surdos que perduraram até finais do século XX.

No Brasil, as escolas proibiam seu uso, coibindo a Língua de Sinais, inclusive, com castigos físicos (STROBEL, 2008, p. 49). Esta proibição e a equiparação de usuários de línguas de sinais com "macacos" intimidava os surdos e tensionava um concepção inferiorizada da surdez:

Uma escola de surdos de uma cidade no interior do Paraná nesta época, colocava quadros de macacos orelhudos e feios em todas as salas de aulas para intimidar as 
LEBEDEFF, T. B.; MADEIRA, D. S.

crianças surdas, quando elas se comunicavam em língua de sinais os professores ligeiramente apontavam para o quadro comparando-as e elas ficavam assustadas com a imagem e se emudeciam (STROBEL, 2008, p. 50).

O texto de Jorge Sérgio apresenta uma concepção de Língua de Sinais depreciativa, refletindo a concepção de Língua de Sinais da época:

Provavelmente os leitores não sabem qual é a diferença entre "surdos-mudos" e "surdosfalantes". Os primeiros não falam, só se expressam por meio da mímica, ao passo que os últimos aprendem a falar e a ler os lábios [...] (GUIMARÃES, 1961, p. 19; publicado originalmente no Shopping News do Rio em 25/05/1958).

Durante muito tempo a Língua de Sinais foi vista apenas como um conjunto de gestos icônicos ou como um código utilizado por um grupo de pessoas "com problemas". Entretanto, a partir da década de 60 do século XX, estudos de fonologia, principalmente os de Stokoe, demonstraram que as Línguas de Sinais eram mais que conjuntos de simples gestos: são línguas estruturadas. Stokoe foi um dos primeiros pesquisadores a analisar a formação dos sinais, sendo que sua publicação Sign Language Structure de 1960 até hoje é obra de referência (MAHER, 1996, p. 24). Quadros (1997, p. 47) explicita que as línguas de sinais são sistemas linguísticos que passaram de geração em geração de pessoas surdas e não são derivadas das línguas orais, mas fluíram de uma necessidade natural de comunicação entre pessoas que não utilizam o canal auditivo-oral, mas o canal viso-espacial.

Os estudos linguísticos sobre Línguas de Sinais eram, portanto, desconhecidos de Jorge Sérgio, que defendia arduamente o método oralista de educação de surdos. Também é interessante constatar que o autor desconhecia a complexidade da Língua de Sinais. Para ele a Língua de Sinais estava restrita ao Alfabeto Manual:

O alfabeto manual, invenção do Abade de L'Epée representa o alfabeto comum em que cada letra é demonstrada por uma diferente posição dos dedos; não traz vantagens por ser prolongado e exaustivo, como também causa embaraços para ouvintes que não entendem o menor sinal. Hoje em dia não se ensina mais o alfabeto manual, nem a mímica convencional dos surdos, mas sim a fala natural e a leitura dos lábios (GUIMARÃES, 1961, p. 19; publicado originalmente no Shopping News do Rio em 29/06/1958).

Jorge Sérgio Guimarães apresenta o Hino ao Surdo Brasileiro, na crônica de mesmo nome, com letra de Astério de Campos e música de Ana Rimoli de Faria Doria, na época diretora 
do Instituto Nacional de Educação de Surdos. O Hino foi entoado na II Olimpíada Nacional de Surdos e mostra a compreensão da época sobre a Língua de Sinais:

\author{
Não mais o ensino antiquado \\ Nos simples dedos das mãos; \\ Com um processo avançado, \\ Salvemos nossos irmãos! \\ Os mudos podem falar! \\ São, de certo, iguais a nós; \\ Compreendem pelo olhar. \\ Aos surdos não falta a voz. \\ (GUIMARÃES, 1961, p. 35, publicado originalmente em Shopping News do Rio em \\ 28/12/1958)
}

Assim como a exaltação ao Hino, outros excertos de crônicas possibilitam a compreensão de que Jorge Sérgio Guimarães não aceitava a Língua de Sinais. Isso se percebia em seus textos que reproduziam os discursos vigentes sobre os efeitos "nefastos" dessa língua no desenvolvimento de pessoas surdas, como no texto "A surdez não é obstáculo":

\begin{abstract}
Não querendo ferir a sensibilidade dos que não puderam aprender a falar, sou contra o uso do alfabeto manual, tão empregado neste país. Sugiro que êle deva ser eliminado para o bem das futuras gerações, pois, não tem mais valor educacional, por se tratar de processo antiquado. Digo que êle só serviria para prejudicar a expansão do "método oral", que oferece à criança surda-muda a possibilidade de falar, dentro de 2 ou 3 anos de assistência, dada por um professor especializado, além da leitura labial, elemento imprescindível para uma conversação (GUIMARÃES, 1961, p. 85; publicado originalmente no Jornal das Moças em 30/6/1960).
\end{abstract}

Para os autores atuais, a Língua de Sinais é determinante na construção da identidade surda. Muitas memórias linguísticas de infância mostram o sentimento de isolamento do surdo no mundo até encontrar a comunidade surda, com a Língua de Sinais e, consequentemente, com todas as possibilidades de compreensão de mundo que uma língua permite (LEBEDEFF, 2006, p. 48).

\title{
3.3 Oralismo
}

Na década de 60, a Língua de Sinais ainda não era considerada língua, mas sim um 
LEBEDEFF, T. B.; MADEIRA, D. S.

código que utilizava-se de gestos ou mímicas. Aos surdos era oferecida a alternativa do Oralismo, que tinha como pressuposto a proibição dos "gestos e mímicas" e buscava uma "normalização" da surdez através de exercícios fono-articulatórios que permitiam a produção da fala e treinamento para leitura labial.

Jorge Sérgio Guimarães informava os leitores e defendia a proposta do Oralismo, como é possível observar na crônica "O Milagre da fala":

O médico Jean Conrad Amman, autor da obra "O surdo que fala", publicada em 1692, acreditava na possibilidade da fala do surdo-mudo, apresentando o seu sistema revolucionário. Mais tarde, o método oral, aperfeiçoado pelo pedagogo alemão Samuel Heinick, teve e continua tendo enorme aceitação entre os principais estabelecimentos de ensino emendativo, no mundo inteiro (GUIMARÃES, 1961, p. 22, publicado originalmente no Shopping News do Rio em 29/6/1958)

Nas suas crônicas o escritor se apresenta como surdo oralizado. O Oralismo é uma concepção educacional que foi predominante na educação dos surdos por mais de um século, a partir do Congresso de Milão realizado em 1880. Ladd compara os surdos oprimidos pelo Oralismo à colonização dos índios americanos:

Tal evidência parece contribuir com respostas para perguntas que, nos últimos anos, a que designei de Ressurgimento Surdo, as pessoas encontraram o espaço psicocultural para começar a fazer: Em que poderia tornar-se uma pessoa Surda e uma comunidade Surda? O que poderíamos ter sido se não nos tivessem tirado a língua gestual e os professores Surdos da educação dos Surdos depois do Congresso de Milão de 1880, uma data tão carregada de significado para nós como é o ano de 1492 para os índios Americanos. O que poderíamos ter sido se não tivéssemos sido forçados a sofrer um século de iliteracia na escrita, sentindo vergonha de nós próprios e estigma? Quem e o que fomos nos séculos que antecederam a chegada de tais proibições, quando os profissionais Surdos e o orgulho Surdo foi supostamente muito mais forte? E o que podemos nós retirar desses tempos que possam informar os passos principiantes que devemos tomar para este século XXI? (LADD, 2013, p. 4).

Sob o ponto de vista de Ladd, o objetivo do oralismo foi aproximar os surdos da sociedade majoritária, ou seja, tornar os surdos "ouvintizados", "normalizados", o que os pesquisadores da educação de surdos consideram uma "opressão ouvintista”. Sérgio Guimarães reproduz o discurso vigente na época, como na crônica “A surdez não é obstáculo":

Por experiência própria, posso afirmar sem receio que o surdo-mudo, na maioria dos casos, torna-se surdo-falante, depois de aprender a falar, até conhecendo um, dois ou mais idiomas. Eu, que já fui surdo-mudo nos primeiros anos, experimentei todas as barreiras, para conseguir emitir os sons vocais. Algo que me afligia. (GUIMARÃES, 
O tom do parágrafo acima é, claramente, muito pessoal. Observa-se que a expressão surdo-mudo era a utilizada na época, já obsoleta hoje em dia. $\mathrm{O}$ autor propõe que surdos podem, sim, aprender a se comunicar oralmente. É importante perceber que atualmente o oralismo não desponta mais como a única opção de educação para os surdos. Atualmente, os surdos adultos decidem pelo processo de oralização como a aprendizagem de uma língua estrangeira. No entanto, é sabido que muitas famílias ainda receiam que a aprendizagem da Língua de Sinais trará prejuízos para as crianças surdas. Essa preocupação, baseada em pesquisas realizadas desde a década de 90, mostra-se equivocada. O Oralismo foi marcante para os surdos, no sentido que se ignoravam as especificidades linguísticas e culturais deles, a exemplo do que Jorge Sérgio Guimarães decerto tenha enfrentado. Suas crônicas refletem situações de interlocutores ignorantes em relação à surdez e Língua de Sinais, o que lhe incomodava com certa frequência. Em nenhum momento a surdez era atendida em suas reivindicações linguísticas e culturais, e, sim, tratada de forma médica. Os surdos eram sempre submetidos linguisticamente à língua majoritária, produzindo sua linguagem e cultura na clandestinidade, enquanto o Oralismo persistia.

A língua dos surdos, durante muito tempo, não foi respeitada além de, muitas vezes, os próprios surdos serem considerados como pessoas com dificuldades cognitivas. Sérgio Guimarães, de acordo com suas crônicas, encontrava-se "inserido" na sociedade majoritária, no entanto, e, ao mesmo tempo, desrespeitado pela maioria das pessoas que o viam como um "doente", como alguém que foi milagrosamente salvo da surdez.

O segundo parágrafo da crônica "A surdez não é obstáculo", acerca da alfabetização, reflete as dificuldades escolares enfrentadas pelo autor no período em que o Oralismo era a única opção e não eram estabelecidas relações entre a Língua Materna (Língua de Sinais) e a Língua Oral:

Quando pequeno tive dificuldade no aprendizado da palavra, a ponto de rebelar-me muitas vezes. No princípio, tudo me pareceu penoso e terrível, mas, à medida que crescia, fui compreendendo que, para alcançar uma pronúncia razoável, era preciso grande força de vontade e treino intenso. (GUIMARÀES, 1961, p. 84; publicado originalmente no Jornal das Moças em 30/06/1960) 
LEBEDEFF, T. B.; MADEIRA, D. S.

Na década de 60, o Oralismo era rigoroso e punitivo, inclusive. São muitos os relatos de surdos deste período que falam de punições físicas por utilizarem "gestos”, ou seja, Língua de Sinais na escola ou em casa. Ladd alerta que, no caso do Oralismo, uma das constantes características do discurso era fazer ostentação de um sucesso surdo individual, mostrando exemplos do "milagre feito de carne", e afirmar assim, que todos - meninas e meninos surdos eram capazes de alcançar esses ganhos. O que se ocultava era que os tomados como exemplos comumente eram crianças que haviam ficado surdos ou que eram parcialmente surdos (LADD, 2003, p. 142).

Nesse sentido, chama a atenção encontrar na crônica "O milagre da fala" uma lista de causas para o não sucesso do método oral em alguns surdos:

\begin{abstract}
Muita gente tem me perguntado porque os surdos-mudos não desfrutam da mesma sorte que os surdos-falantes. Devo dizer que são diversos os motivos que bem podem explicar a sua situação: a) dificuldades financeiras para a educação necessária; b) impossibilidade orgânica, por exemplo: falta de úvula e do véu palatino; c) ausência do treino da fala e leitura labial e da linguagem comum, usada pelas pessoas que lhes falam; d) influência sofrida pela conduta dos pais no próprio lar; e) inteligência pouco desenvolvida; f) ambiente de incompreensão e intolerância no meio doméstico, social e profissional; g) má companhia que pode ser prejudicial à higiene mental (GUIMARÃES, 1961, p. 2122; publicado originalmente no Shopping News do Rio em 29/6/1958).
\end{abstract}

Com relação ao ensino oralista, Jorge Sérgio Guimarães, em diferentes crônicas, informa aos leitores sobre as escolas oralistas da época, como a escola Helen Keller no Rio de Janeiro, o Instituto Nacional de Educação de Surdos, o Instituto Santa Teresinha em São Paulo, o Lexington School for the Deaf, nos Estados Unidos, o Gallaudet College também nos Estados Unidos, entre outras, (GUIMARÃES, 1961, p. 30-63). O autor exalta o sucesso de professoras oralistas na crônica "Instituto Santa Teresinha":

Suas professoras são diplomadas e especializadas, com largo tirocínio em institutos similares da Europa, e o ensino é ministrado, de acordo com os métodos mais modernos, sendo completamente banido o emprego da mímica. (GUIMARÃES, 1961, p. 39, originalmente publicado no Shopping News do Rio em 22/2/1959)

De acordo com Ladd (2003, p. 148), depois do congresso de Milão, ou seja, nos primeiros anos do século XX, no mundo inteiro, os surdos eram subalternos, praticamente sem permissão para expressar seus pensamentos e tampouco foram atendidos os almejos deles quando o assunto 
era a questão da língua de sinais ou dos seus privilégios linguísticos.

\section{CONSIDERAÇÕES FINAIS}

$\mathrm{Na}$ década de 60 do século XX iniciaram os primeiros estudos e indicativos de que a Língua utilizada pelos surdos não eram apenas mímicas, mas, língua constituída. O conceito de surdez, então, era de uma situação incapacitante e limitadora. Jorge Sérgio incita os surdos a estudarem, utiliza como exemplo a Universidade de Gallaudet, nos EUA. Questiona o impedimento legal dos surdos dirigirem carros, dando exemplos de outros países. Salienta a importância de que os surdos sejam oralizados para que tenham sucesso escolar e profissional.

É sabido, através de suas crônicas, que o autor não conheceu a Universidade de Gallaudet e nem o uso fluente da Língua de Sinais nos Estados Unidos. Seu parâmetro de surdez e Língua de Sinais era formado pelo contato com surdos brasileiros, pelas representações de surdez correntes e por informações que lhe chegavam através de viajantes e material impresso no Brasil. Seus escritos são uma fotografia de um período no qual os surdos eram vistos como doentes que deveriam ser "normalizados". Sua importância para a comunidade surda atual refere-se ao seu papel de cronista surdo da história dos surdos nas décadas de 50 e 60 no Brasil. Ou seja, Jorge Sérgio Guimarães não escreve no lugar do outro. Ao falar de si, da sua surdez e das representações de surdez vigentes na época, tem-se o registro de uma memória que deve ser compreendida e problematizada.

Analisar a memória de grupos estigmatizados, considerados como diferentes, permite averiguar as representações, explícitas ou não, que levaram ao alijamento dessas pessoas pelas classes sociais majoritárias e, possibilita compreender as memórias e identidades que se forjam na situação de exclusão. Nesse sentido, Félix (1998, p. 45) ressalta que:

Estudar memória, entretanto, é falar não apenas de vida e de perpetuação da vida através da historia; é falar, também, de seu reverso, do esquecimento, dos silêncios, dos nãoditos, e, ainda, de uma forma intermediaria, que é a permanência de memórias subterrâneas entre o esquecimento e a memória social.

O livro de Jorge Sérgio Guimarães, sugere-se, é uma preciosidade da história e da 
LEBEDEFF, T. B.; MADEIRA, D. S.

memória dos surdos brasileiros e, muito ainda tem a contribuir para compreender a surdez nas décadas de 50 e 60 do século XX no Brasil.

\title{
THE CHRONICLES OF JORGE SERGIO L. GUIMARÃES AND THE REPRESENTATIONS OF DEAFNESS IN THE DECADES OF 1950 AND 1960
}

\begin{abstract}
This paper proposes to analyse and discuss texts published by the writer Jorge Sergio L. Guimarães between the 1950`s and 60`s. The writer, who was deaf, published his small Chronicles as a collaborator in three journals: Jornal das Moças, Shopping News do Rio e Jornal O Globo. In 1961, the texts were compiled in the book "Até onde o surdo vai ". The narratives are evidence of a hegemonic discourse on deafness that was, at the same time, clinic and oralist, typical of the period and prior to the beginning of the linguistic and anthropological studies of sign languages and deafness. The present work analyses the concepts of deafness, oralism and sign language, while at the same time presents Jorge Sergio L. Guimarães as an important chronicler of the deafness.
\end{abstract}

Keywords: Representation; Deafness; Sign Language; Oralism; Memory

\section{LAS CRONICAS DE JORGE SERGIO L. GUIMARÃES Y LAS REPRESENTACIONES ACERCA DE LA SORDERA EN LAS DECADAS DE 1950 Y 1960}

\section{Resumen}

Este trabajo tiene como objetivo analizar y discutir los textos publicados por Jorge Sergio L. Guimarães entre los años 50 y 60. El escritor, que era sordo, publicaba sus pequeñas crónicas, como colaborador en tres periodicos: Jornal das Moças, Shopping News do Rio y O Globo. En 1961, los textos fueron recopilados en el libro "Até onde o surdo vai ". Las narrativas evidencian un discurso hegemónico sobre la sordera, al mismo tiempo clínico y oralista, típico de la época y, anterior al inicio de los estudios lingüísticos y antropológicos de la Lengua de Señas y sordera. Este trabajo analiza los conceptos de sordera, oralismo y la lengua de señas, al mismo tiempo que 
AS CRÔNICAS DE JORGE SÉRGIO L. GUIMARÃES E AS REPRESENTAÇÕES DA SURDEZ ENTRE AS DÉCADAS DE 1950 E 1960

presenta Jorge Sérgio L. Guimarães como cronista importante de la sordera.

Palabras clave: Representación; Sordera; Lengua de Señas; Oralismo; Memoria

\section{REFERÊNCIAS}

CANDEAU, Joel. Memória e identidade. São Paulo: Contexto, 2011.

CLAROS-KARTCHNER, R. La Inclusión de las personas sordas, como grupo étnico, en los sistemas educativos. Revista Latinoamericana de Educación Inclusiva. Vol 3, No. 1, 63-75, 2009.

FÉLIX, Loiva O. História e memória: a problemática da pesquisa. Passo Fundo: UPF Editora, 1998.

Política, memória e esquecimento. In: TEDESCO, J.C. (Org.) Usos de memórias:

política, educação e identidade. Passo Fundo: UPF Editora, 2002.

FIGUEIREDO, Ivan Vasconcelos. Discurso, poder e representações: o dizer oficial sobre a surdez. Disponível em: 〈http://www.fflch.usp.br/dlcv/enil/pdf/83_Ivan_VF.pdf〉. Acesso em: 29 set. 2015.

GIORDANI, Liliane Ferrari. Representações culturais da escrita: letramentos e educação de jovens e adultos surdos. In: V Seminário de Pesquisa em Educação da Região Sul, 2004. Anais do V Seminário de Pesquisa em Educação da Região Sul, Curitiba: Editora da PUCPR, 2004. 1 CD-Rom.

GUIMARÃES, Jorge Sérgio L. Até onde vai o surdo. Rio de Janeiro-RJ: Editora Gráfica Tupy Ltda, 1961.

HALL, Stuart. Representation: Cultural Representations and Signifying Practices. London: Sage Publications, 1997.

HALL, Stuart. A identidade Cultural na Pós-modernidade. Rio de Janeiro: DP\&A. Editora, 2002.

JOVCHELOVITCH, Sandra e BAUER, M., Entrevista Narrativa. In: BAUER, Martin W. GASKELL, G. Pesquisa Qualitativa com Texto, Imagem e Som: um manual prático. Petrópolis: Vozes, 2008.

KARNOPP, Lodenir Becker. Produções culturais de surdos: análise da literatura surda. Cadernos de Educação. Pelotas: Universidade Federal de Pelotas. [36]: 155 - 174, 2010. 
LEBEDEFF, T. B.; MADEIRA, D. S.

LADD, Paddy. Comprendiendo la cultura sorda. En busca da surdidade. Concepción. Chile: Editora Fundo Nacional de Fomento del libro e da leitura, 2003.

Em busca da surdidade. Lisboa-Portugal: Editora Surd'Universo, 2013.

LANE, Harlan. Constructions of deafness. Disability \& Society. Vol 2, No. 10, 171-190, 1995.

LANE, Harlan. Ethics, and the Deaf-World. Journal of Deaf Studies and Deaf Education, Vol. 10, No. 3, pp. 291-310, 2005.

LEBEDEFF, Tatiana Bolivar. O que lembram os surdos de sua escola: discussão das marcas criadas pelo processo de escolarização. In: Thoma, A. S. e Lopes, M. C. (Orgs.) A invenção da Surdez II: espaços e tempos de aprendizagem na educação de surdos. Santa Cruz: Edunisc, 2006.

LOPES, Maura Corcini. Relações de poderes no espaço multicultural da escola para surdos. In: SKLIAR, C. (Org.) A surdez: um olhar sobre as diferenças. Porto Alegre: Mediação, 1998.

A noção de comunidade e a língua surda no espaço da escola de surdos. In: LEBEDEFF, T.B. e PEREIRA, I.L.S. (Org.) Educação especial: olhares interdisciplinares. Passo Fundo: UPF, 2005.

MAHER, Jane. Seeing language in sign: the work of William C. Stokoe. Washington: Gallaudet University Press, 1996.

OBASI, Chijoke. Seeing the Deaf in "Deafness"'. Journal of Deaf Studies and Deaf Education 13:4 Fall, 2008.

POKORSKI, Juliana. O. Representações na literatura surda: produção da diferença surda no curso de letras-libras. Dissertação de Mestrado não publicada. Porto Alegre: UFRGS, 2014. Disponível em: <http://www.lume.ufrgs.br/handle/10183/107941>. Acesso em: 29 set. 2015.

QUADROS, Ronice Muller de. Educação de surdos: A aquisição da linguagem. Porto Alegre: Artes Médicas, 1997.

STROBEL, Karin. Surdos: Vestígios Culturais não Registrados na História. Tese de Doutorado em Educação - UFSC - Universidade Federal de Santa Catarina. Florianópolis, 2008.

SKLIAR, Carlos. Estudos surdos e estudos culturais em educação. In: LACERDA, C. B. F.; GÓES, M. C. R. (Orgs.) Surdez: processos educativos e subjetividade. São Paulo: Lovise, 2000.

THOMA, Adriana da Silva. O cinema e a flutuação das representações surdas: Que drama se desenrola neste filme? Depende da perspectiva.... Dissertação de Mestrado não publicada. Porto Alegre: URGS, 2002. Disponível em: <http://www.lume.ufrgs.br/handle/10183/37838>. Acesso em: 29 de Set. 2015. 
AS CRÔNICAS DE JORGE SÉRGIO L. GUIMARÃES E AS REPRESENTAÇÕES DA SURDEZ ENTRE AS DÉCADAS DE 1950 E 1960

THOMA, Adriana da Silva. A constituição do espaço escolar como possibilidade de correção e normalização do sujeito surdo. In: LEBEDEFF, T.B. e PEREIRA, I.L.S. (Org.) Educação Especial: olhares interdisciplinares. Passo Fundo: UPF, 2005.

Data de recebimento: 29/05/2015

Data de aceite: 27/10/2015 